\title{
THERMAL CHARACTERIZATION OF DIFFERENT GRAPHITE POLYSTYRENE
}

\author{
Á. LAKATOS $^{1, *}$, I. DEÁK ${ }^{1}$, U. BERARDI ${ }^{2}$ \\ ${ }^{1}$ Department of Building Services and Building Engineering, University of Debrecen, Hungary \\ ${ }^{2}$ Department of Architectural Science, Ryerson University, Toronto, ON, Canada \\ *E-mail: alakatos@eng.unideb.hu
}

\begin{abstract}
The development of high performance insulating materials incorporating nanotechnologies has enabled considerable decrease in the effective thermal conductivity. Besides the use of conventional insulating materials, such as mineral fibers, the adoption of new nano-technological materials such as aerogel, vacuum insulation panels, graphite expanded polystyrene, is growing. In order to reduce the thermal conductivity of polystyrene insulation materials, during the manufacturing, nano/micro-sized graphite particles are added to the melt of the polystyrene grains. The mixing of graphite flakes into the polystyrene mould further reduces the lambda value, since graphite parts significantly reflect the radiant part of the thermal energy. In this study, laboratory tests carried out on graphite insulation materials are presented. Firstly, thermal conductivity results are described, and then sorption kinetic curves at high moisture content levels are shown. The moisture up-taking behaviour of the materials was investigated with a climatic chamber where the relative humidity was $90 \%$ at $293 \mathrm{~K}$ temperature. Finally, calorific values of the samples are presented after combusting in a bomb calorimeter.
\end{abstract}

Keywords: graphite polystyrene, thermal conductivity, wetting insulation, kinetic curves

\section{Introduction}

The reduction of the energy demand of a building is mainly achieved by applying thermal insulation materials on the external enclosures. The use of polystyrene or wool materials is dominant, although the application of innovative nanotechnology-enhanced insulation is widespread. In most countries, thanks to the cheap manufacturing processes, polystyrene is a valuable material for additional insulation of existing buildings [1-3]. Expanded polystyrene (EPS) is mainly reached by evaporating the pentane to gas phase added into the polystyrene balls. Through this process white, rigid and open or closed cell foam will be formed [4]. To further reduce the thermal conductivity of the polystyrene insulation materials, graphite nanotubes or carbon particles can be added to the polystyrene grains during the manufacturing procedure, since these materials have much lower thermal conductivity $(0.03 \mathrm{~W} / \mathrm{mK})$ than the pure EPS.

The effective heat flow through the sample layer can be mainly thought as a sum of conduction across the solid matrix, convection of the internal gases in the pores and radiation among the solid surfaces. It should be mentioned that during a heat transfer process, several heat transfer modes occur (so conduction, convection, and radiation coexist), but one of them often dominates. Conduction and convection show linear dependence from the temperature across a layer of insulation, while radiation has an exponential change with the temperature difference [5]. Ferkl et al. found that the major drawback of low density bulk polymeric foams is the large amount of thermal radiation (2040\%) [6]. Minh-Phuong Tran et al. found that adding different types of graphite particles (surface-modified nano-graphite particulates, carbon nanotubes, disperse graphene fillers, or graphene oxide) to the polystyrene grains during the manufacturing process, the thermal conductivity of the composite can be lower significantly [7]. Graphite has very good infrared radiation absorbing capability and it has a beam scattering behaviour, too. In recent years, polymer composite materials such as EPS with graphite have attracted increasing attention as the new generation of EPS given their low thermal conductivity. Since insulation ma-

This is an open-access article distributed under the terms of the Creative Commons Attribution-NonCommercial 4.0 International License (https://creativecommons.org/licenses/by-nc/4.0/), which permits unrestricted use, distribution, and reproduction in any medium for non-commercial purposes, provided the original author and source are credited, a link to the CC License is provided, and changes - if any - are indicated. 
terials applied for building structures are effected to various temperatures and moisture levels depending on the different climatic and the environmental conditions, more investigation of the effective in field behaviours of these new products is needed. In fact, it is worthy to take environmental field circumstances into account when characterizing the thermal performance of an insulation material. For example, extremely high humidity levels may deteriorate the insulation integrity, increase the weight, and support mould growth and bacteria [8]. More importantly, moisture presence in an insulation material negatively changes its thermal performance [9]. Besides the measurement of the thermal conductivity of insulation materials, moisture absorption test should be carried out. A valuable important property of expanded polystyrene is its water un-permeability or resistance. A reciprocal function between the density and water content is presented by Lakatos and Kalmár in [2] and by Gnip et al. in [10]. Besides the operating temperature, the moisture content inside the material has a significant factor on the thermal conductivity due to the presence of a liquid phase $[11,12]$. In this paper, both thermal conductivity and moisture absorption tests of graphite EPS insulation materials provided from five different manufacturers will be presented.

\section{Materials and calculation methods}

\subsection{The used samples}

Five graphite-enhanced expanded polystyrene insulation materials produced by different manufacturers were analysed in this paper; Table 1 reports the samples tested in this paper.

For the thermal conductivity measurements, $5 \mathrm{~cm}$ thick samples were received from the companies, then they were cut in shapes of approximately $30 \times 30 \mathrm{~cm}$. For the sorption kinetic investigations, samples with $10 \times 10 \mathrm{~cm}$ were used.

\subsection{The wetting kinetic curves and moisture absorption}

The wetting measurements were carried out following the ISO standards 12571 and 15148. These standards prescribe the measurement orders both for the sorption isotherms measurements and for the determination of the water absorption coefficient.

The wetting experiments were executed after desiccating the samples in a VentiCell drying chamber to changeless weight in accordance to the above mentioned standard. Constant mass can be considered if the change of mass among three consecutive weight measuring made 24 hours apart, is less than $0.1 \%$ of the total mass. In this equipment, the samples were dried at $70{ }^{\circ} \mathrm{C}$ ambient temperature. The drying temperature was chosen because during the thermal annealing process at this temperature, the samples do not suffer any changes in their physical and chemical properties; furthermore, this temperature is rather less than the melting point of the EPS materials. The ambience of the air inside the chamber can be reached by an inbuilt ventilator. To determine the wetting kinetic curves, three samples from each type were kept at $293 \mathrm{~K}$ temperatures in the climatic chamber under

Table 1. Photos of the tested samples with indication of their densities and dimensions

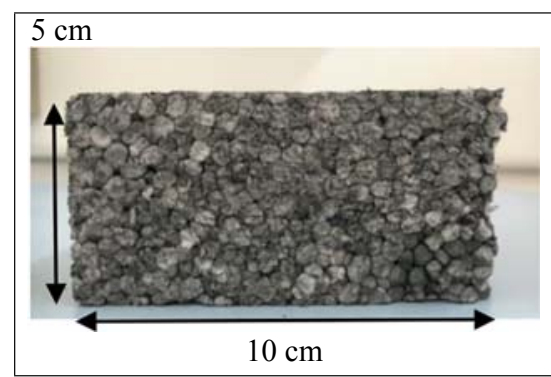

No. $1: 17.13 \mathrm{~kg} / \mathrm{m}^{3}$

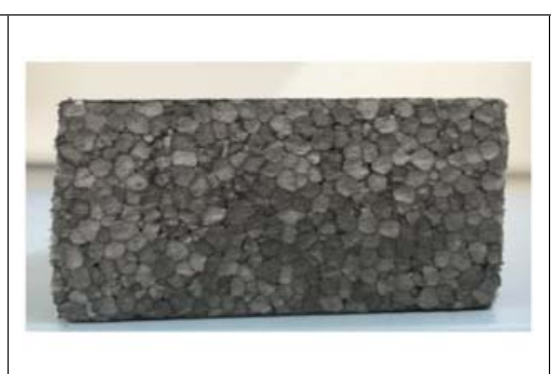

No. $2: 14.35 \mathrm{~kg} / \mathrm{m}^{3}$

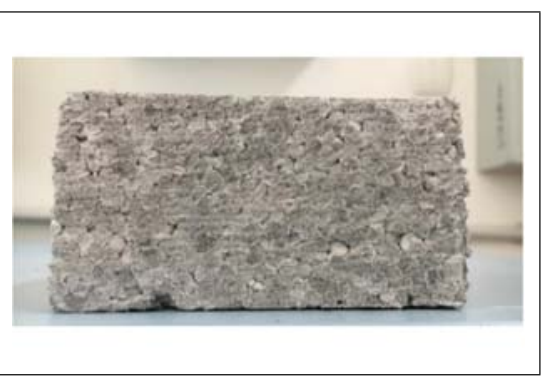

No. $3: 15.40 \mathrm{~kg} / \mathrm{m}^{3}$

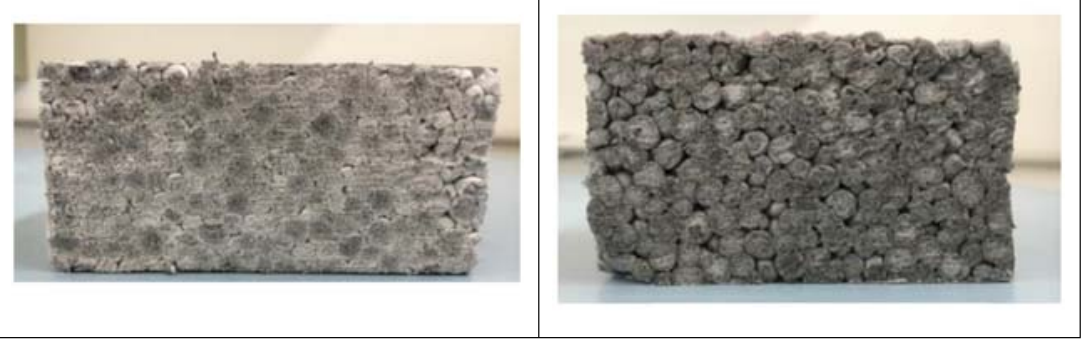

No. $4: 15.06 \mathrm{~kg} / \mathrm{m}^{3}$

No. $5: 16.52 \mathrm{~kg} / \mathrm{m}^{3}$ 
$90 \% \mathrm{RH}$ for $20,40,60,120,240,450,960$ and 1440 minutes ( 24 hours). For each wetting time, dried samples were used. The water/moisture content $(\omega \%)$ of a solid material can be reached from the following equation:

$$
\omega\left(\frac{g}{g} \%\right)=\frac{m_{w}-m_{d}}{m_{d}} \times 100,
$$

where, $m_{d}$ and $m_{w}$ are the masses of the dried and humid samples, respectively. The results were evaluated by averaging the three measurement results after a certain wetting time at $90 \%$ relative humidity, and $60{ }^{\circ} \mathrm{C}$ temperature. The ISO 15148 reports the method for the determination of the water absorption coefficient of the materials. This standard suggests estimating the $A_{w}$ value with direct contact of the water (partial immersion) as:

$$
A_{w}=\frac{m_{w}-m_{d}}{A \sqrt{t}},
$$

where $A_{\mathrm{w}}$ is the water absorption coefficient in $\mathrm{kg} / \mathrm{m}^{2} \mathrm{~s}^{1 / 2}$. As the definition, the water absorption coefficient $A_{w}$ can be reached by the slope of the fitted curve divided by the contact area $(A)$ and the square root of the time. One of the main moisture transport properties is its water absorption coefficient. Mukhopadhyaya et al. investigated the water absorption coefficient of different materials through immersion test [15]. As their definition water absorption coefficient of a material manages the liquid moisture movement into it. Its relation to moisture/liquid diffusivity was also researched. They investigated further the effect of the surface temperature in the absorbed amount of water. Thinking further these directions, the method can be applied for the measurements carried out with humidity (climatic) chamber at high relative humidity $(\sim 90 \%)$ where direct contact with the liquid water cannot be observed. By understanding a normal sorp- tion isotherm curve where it is indicated that over $80 \%$ relative humidity the most quantity of the water occurs in liquid phase, as shown in Fig. 1 [16].

\subsection{The thermal conductivity measurements}

The measurements were executed according to the ISO 12664 standard. The measurements were carried out after drying to changeless weight at $70^{\circ} \mathrm{C}$ similarly as mentioned above. In order to measure the thermal conductivity of each graphite polystyrene sample, a Holometrix 2000 Heat flow meter (HFM) was utilised. The apparatus is designed to determine the thermal conductivity of insulation materials in agreement with standard ASTM C518.

Five different graphite EPS samples, each type with about $30 \times 30 \times 5 \mathrm{~cm}$ geometry were positioned in the test area between two plates which were kept at different temperatures $\left(T_{1}=12{ }^{\circ} \mathrm{C}\right.$ and $\left.T_{2}=22{ }^{\circ} \mathrm{C}\right)$ during the measurement. After reaching thermal equilibrium and raising a uniform temperature gradient within the material, thermal conductivity is determined. To determine the lambda value of a sample, five tests were executed on each. The final result of analysed material was the average value of the five measured results according to the ISO 10456 [17].

\subsection{The declared thermal conductivity}

At macroscopic level, the effective thermal conductivity largely depends on the following factors: pressure $(p)$, density $(\rho)$, moisture content $(\omega)$, temperature $(T)$, and its age [18]:

$$
\lambda=f(p, \rho, \omega, T, \text { age })
$$

In accordance with the ISO 10456 standard, the influence of moisture, temperature and age are inde-

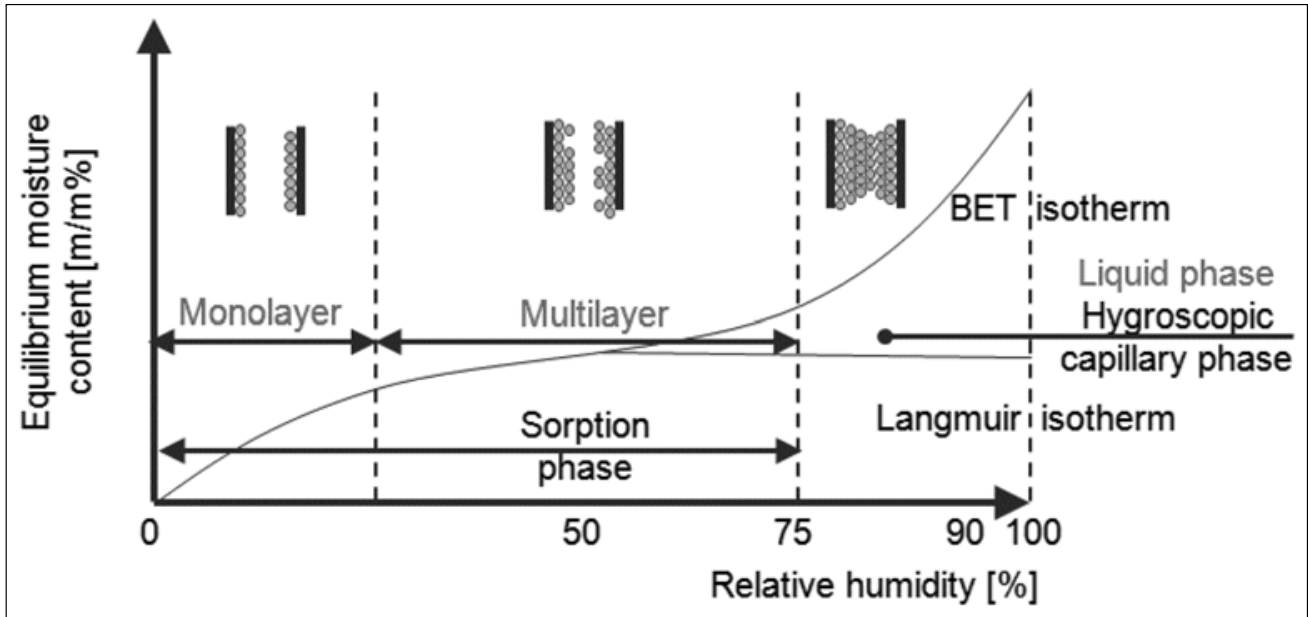

Fig. 1. Sorption isotherm curves (the values of relative humidity divided different moisture accumulation processes are hypothetical and would vary depend on the material, too) 
pendent, and can be written as Eq. (3). By using the directions of this standards from the measured thermal conductivities, declared thermal conductivities will be given at $10^{\circ} \mathrm{C}$ temperature. The full procedure for the calculation of the declared values is reported in Refs $[5,18,19]$.

\subsection{Measurements of the combustion heat}

Bomb calorimetry is a method to determine the heat of burning or calorific value of solid and liquid materials which are combusted. It is one of the main tests of great importance in order to exactly know the burning and firing properties of the samples. Theory of dry isothermal Calorific Value (CV) measurements is the following. The $\mathrm{CV}$ of a material is determined by firing it in a controlled environment (adiabatic chamber). The evaluated heat released by this burning, namely the net temperature difference depends from the calorific value. In the adiabatic chamber, the thermal environment is controlled so that no energy lost or gain is expected. $\mathrm{CV}$ values were measured by using this apparatus after drying the three samples from each type of GEPS insulating material. After the individual measurements the average of the $\mathrm{CV}$ values and the estimated errors were calculated and represented.

\section{Results and discussion}

\subsection{The moisture kinetic curves and water absorption graphs}

In Fig. 2 showing the kinetic curves, it is possible to see the time evolution of the moisture up-taking pro- cess. One can conclude that in most of the cases the equilibrium occurred. We cannot declare in the first case (No. 1 sample) that the process of the filling up of the pores is finished during the given time. For the cases No. 2, No. 3 and No. 4, nearly the same quantities were measured. The highest water content was detected for sample No. 1 and by No. 5 .

In Fig. 3, the amount of the sorped water in function of the square root of the time is depicted for all cases. It is feasible to estimate as using the theory introduced in Section 2.2, before the equilibrium state a "value" similar to the water absorption coefficient presented in the ISO 15148 can be deduced. These values are indicated in the graph. The highest the values the highest the affinity to take up water is. For samples No. 1, 3 and 5, nearly the same quantities were manifested, while the highest value was reached for the sample No. 2.

\subsection{The result of the thermal conductivity measurements}

Firstly, thermal conductivity measurements were carried out on each sample. From the measurement results declared values were calculated to $10^{\circ} \mathrm{C}$ by using the calculation procedure of the standard ISO 10456 see Ref. [17] and were compared to the values given by the manufacturers. From Fig. 4, it is observable that in all cases the calculated declared values are higher than the other two lambda values. The results of the samples No. 1, No. 2, and No. 4 are showing nearly the same trends, with similar differences among the values.

Here it has to be noticed that the values given by the manufacturers are lower than the other values ex-

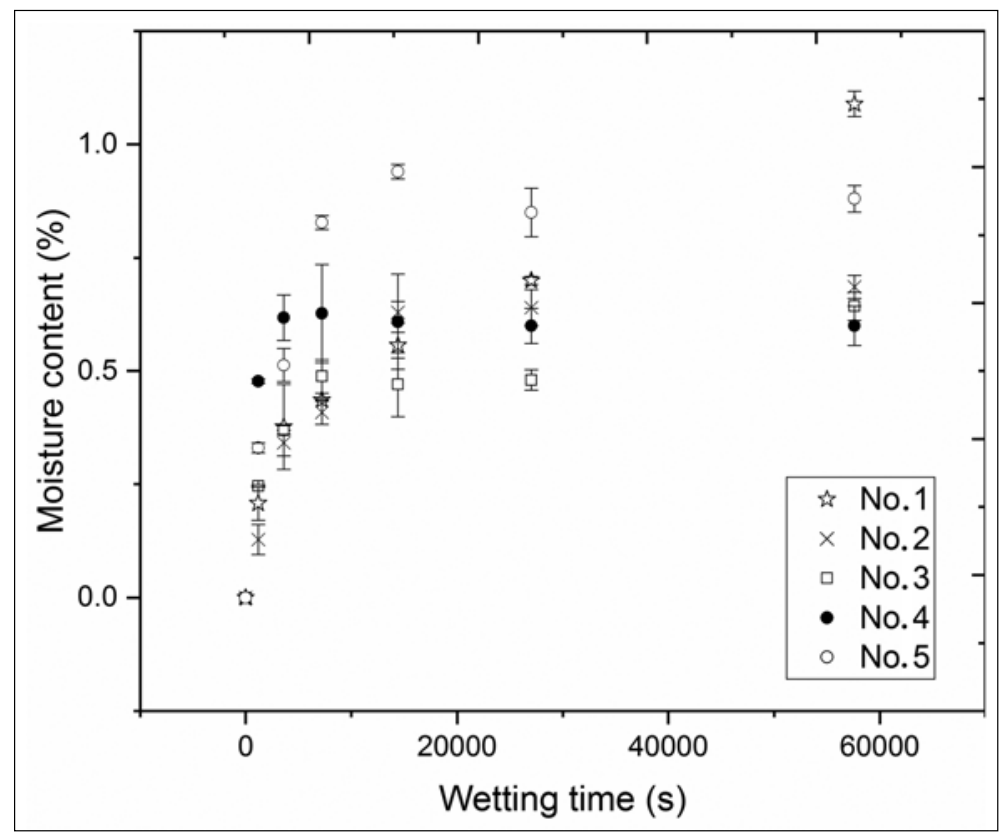

Fig. 2. Moisture kinetic curves of the samples investigated in this paper 


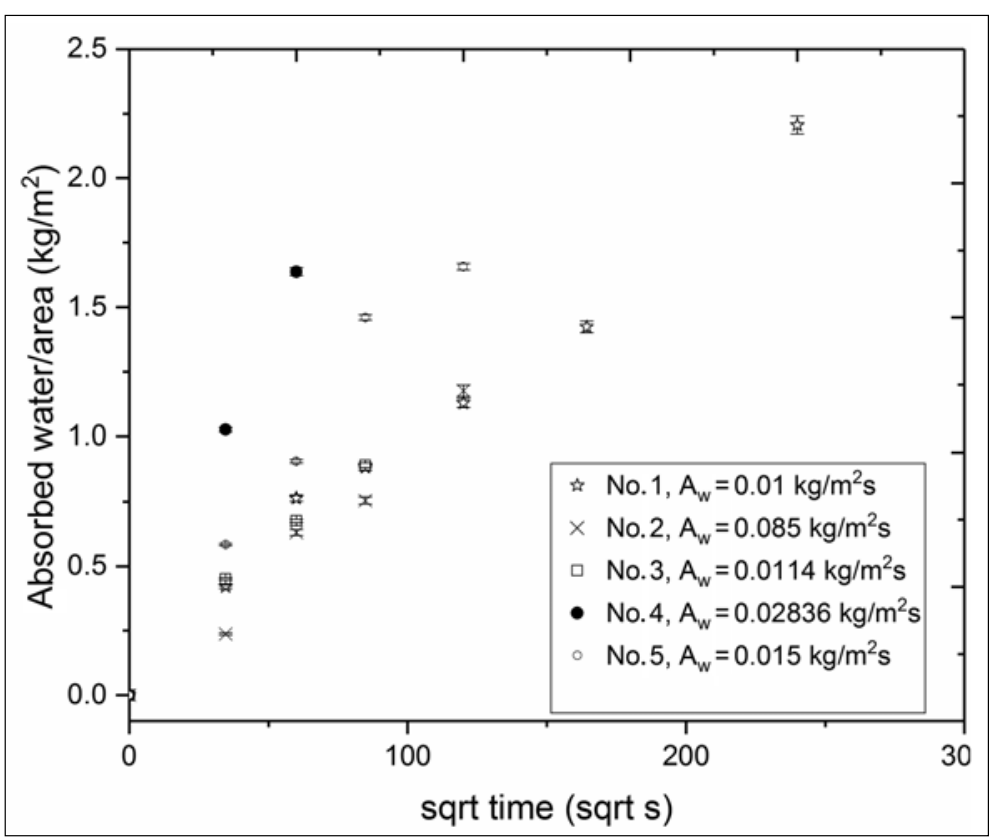

Fig. 3. Moisture absorption graphs of the samples investigated in this paper

cept for the results of the sample No. 3. The difference between the measured value and the calculated declared value originates from the calculation method. At first, for the calculation the mean value and the standard deviation should be given, by knowing the limit value for the tolerance interval. In the cases of sample No. 3 and No. 5 one can observe great difference between the declared values and the measured ones. It resulted from their high standard deviation value and from the high dispersion in their measured values.

\subsection{Measurement of the combustion heat}

In addition to the above presented measurements, the calorific value of the samples were also measured by using Cal2 Eco oxygen bomb calorimeter. In Table 2, the measured calorific values and the absolut errors fo the measurements are reported. In this table it can be observed that the results are in the same order of magnitude, with no significant differences.

Table 2. Measured calorific values of the samples investigated in this paper

\begin{tabular}{lcc}
\hline Samples & Calorific value $[\mathrm{MJ} / \mathrm{kg}]$ & Abs. Err. \pm \\
\hline No. 1 & 35.45 & 1.02 \\
No. 2 & 33.59 & 0.62 \\
No. 3 & 37.68 & 1.00 \\
No. 4 & 34.10 & 1.65 \\
No. 5 & 35.15 & 1.69 \\
\hline
\end{tabular}

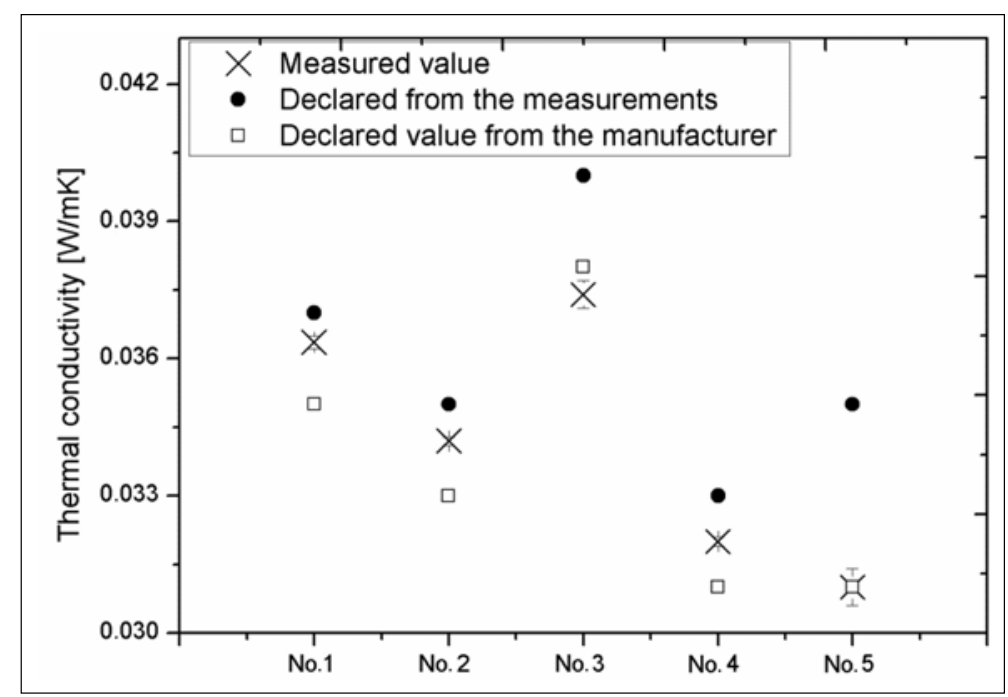

Fig. 4. Thermal conductivities values of the samples investigated in this paper 


\section{Conclusions}

In this article, laboratory measurements were carried out on five different graphite-enhanced polystyrene insulations and the results were combined with calculations. Measurements were executed in particular to the thermal conductivity, water up-taking capability and calorific value. By using standards and theories declared thermal conductivities and values similar to the water absorption coefficient were deduced. From the measurement results we can state that different types of graphite EPS materials behave differently from the thermal investigations point of view. They have different thermal conductivities and they show different behaviour in the humid environment. These deviances can originate from the different processes of manufacturing, but mostly originate from the different amount of graphite particles added to the material's matrix. The number of the pores and the pore structure, as well as the amount of graphite particles regulates mainly the value of the thermal conductivity and the amount of the water taken up. The homogeneity of each type of the samples will result small standard deviations for the calculated thermal conductivities. The results can also be important for practitioners, designers and for manufacturers.

\section{Acknowledgements}

This project was co-financed by the European Union and the European Social Fund through the EFOP3.6.1-16-2016-00022 project.

\section{References}

[1] Kalmár F. (2002), Energy analysis of building thermal insulation. In: 11th Conference for Building Physics, 2002 Sept 26-30, Dresden, Germany, pp. 103-112.

[2] Lakatos Á., Kalmár F. (2013), Analysis of water sorption and thermal conductivity of expanded polystyrene insulation materials. Building Services Engineering Research and Technology, 34, 407-416.

[3] Lakatos Á., Kalmár F. (2013), Investigation of thickness and density dependence of thermal conductivity of expanded polystyrene insulation materials. Materials and Structures, 46, 1101-1105.

[4] Schiavoni S., D’Alessandro F., Bianchi F., Asdrubali F. (2016), Insulation materials for the building sector: A review and comparative analysis. Renewable and Sustainable Energy Reviews, 62, 988-1011.
[5] Berardi U., Naldi M. (2017), The impact of the temperature dependent thermal conductivity of insulating materials on the effective building envelope performance. Energy and Buildings, 144, 262-275.

[6] Ferkl P., Pokorny R., Bobak M., Kosek J. (2013), Heat transfer in one-dimensional micro- and nano-cellular foams. Chemical Engineering Science, 97, 50-58.

[7] Tran M. P., Gong P., Detrembleur C., Thomassin J. M., Buahom P., Saniei M., Kenig S., Parka C. B., Lee S. E. (2016), Reducing Thermal Conductivity of Polymeric Foams with High Volume Expansion Made From Polystyrene/Expanded Graphite. SPE ANTE, 1870-1882.

[8] Koru M. (2016), Determination of thermal conductivity of closed-cell insulation materials that depend on temperature and density. Arabian Journal for Science and Engineering, 41, 4337-4346.

[9] Cai S., Zhang B., Cremaschi L. (2017), Review of moisture behavior and thermal performance of polystyrene insulation in building applications. Building and Environment, 123, 50-65.

[10] Gnip I. Y., Kersulis V., Vejelis S., Vaitkus S. (2006), Water absorption of expanded polystyrene boards. Polymer Testing, 25, 635-641.

[11] Nosrati R. H., Berardi U. (2018), Hygrothermal characteristics of aerogel-enhanced insulating materials under different humidity and temperature conditions. Energy and Buildings, 158, 698-711.

[12] Berardi U., Nosrati R. H. (2018), Long-term behaviour of aerogel-enhanced insulating materials under different aging laboratory conditions. Energy, 147, 1188-1202.

[13] ISO 12571 (2013), Hygrothermal performance of building materials and products - Determination of hygroscopic sorption properties, Part B - Climatic chamber method.

[14] ISO 15148 (2002), Hygrothermal performance of building materials and products - Determination of water absorption coefficient by partial immersion.

[15] Mukhopadhyaya P., Kumaran K., Normandin N., Goudreau P. (2002), Effect of surface temperature on water absorption coefficient of building materials. Journal of Thermal Envelope and Building Science, 26(2), 179-195.

[16] Brunauer S., Deming L. S., Deming W. E., Teller E. (1940), On a theory of the van der Waals adsorption of gases. Journal of American Chemical Society, 62, 1723-1732.

[17] ISO 10456, Building materials and products - Hygrothermal properties - Tabulated design values and procedures for determining declared and design thermal values.

[18] Lakatos Á. (2017), Thermal conductivity of insulations approached from a new aspect. Journal of Thermal Analysis and Calorimetry. https://doi.org/10.1007/s10973-0176686-5.

[19] Munoz D. F., Anderson B., Cejudo-Lópeza J. M., Carrillo-Andrés A. (2010), Uncertainty in the thermal conductivity of insulation materials. Energy and Buildings, 42(11), 2159-2168. 